http://nv.nltu.edu.ua

https://doi.org/10.15421/40280523

Article received 14.05.2018 p.

Article accepted 31.05.2018 p.

ISSN 2519-2477 (online)

УДК 536.2.083

$@ \bowtie$ Correspondence author

Ya. P. Yusyk

yusik@ukr.net

І. С. Васильківський, В. О. Фединець, Я. П. Юсик

Начіональний університет "Львівська політехніка", м. Львів, Украӥна

\title{
ВИМІРЮВАННЯ ТЕПЛОПРОВІДНОСТІ ЛИСТОВИХ МАТЕРІАЛІВ З УРАХУВАННЯМ КОНТАКТНИХ ТЕПЛОВИХ ОПОРІВ
}

Розглянуто питання впливу контактних теплових опорів (КТО) на точність вимірювання теплопровідності матеріалів. Наведено конструкцію пристрою для визначення значень КТО. В основі пристрою є пакет із двох пар плоских зразків, розміщених у різній послідовності між джерелом тепла і приймачами тепла однакової температури. Один із зразків у всіх парах має одну і ту саму товщину, другий зразок у двох парах пакета відрізняється за товщиною вдвічі. Реєструють тепловий потік через пакети, різницю температур між серединними зразками пакетів та перепад температур на тонкому зразку і за отриманими даними розраховують шукану величину. Подано результати експериментального визначення КТО між різними матеріалами. Показано, що знехтувати впливом КТО на результат вимірювання у визначенні коефіцієнта теплопровідності різних матеріалів (особливо високотеплопровідних) не можна, оскільки він співвимірний з тепловими опорами досліджуваних зразків. Для виключення цього впливу на результат вимірювання теплопровідності розроблено вимірювальний перетворювач для вимірювання теплопровідності листових матеріалів на основі мостової теплової вимірювальної схеми. Наведено схему з'єднання теплових опорів і КТО, розподілу теплових потоків і температур у зрівноваженій мостовій тепловій вимірювальній схемі та принципову схему вимірювального перетворювача теплопровідності листових матеріалів.

Ключові слова: коефіцієнт теплопровідності; мостова теплова вимірювальна схема; досліджуваний зразок; еталонний зразок; тепловий опір контакту; площа контакту.

Вступ. Під час контакту теплопровідних шарів на поверхні їх поділу виникає контактний тепловий опір (КТО). Цей опір виникає тоді, коли поверхні двох матеріалів недостатньо щільно притиснуті одна до одної й між ними залишається тонкий шар рідини чи газу. Дослідження контакту між твердими поверхнями показує, що матеріали торкаються один до одного лише вершинами профілів шорстких поверхонь, а впадини поверхонь контакту заповнені іншим середовищем: повітрям, рідиною або вакуумом.

Механізм теплопередавання в зоні поверхонь контакту є досить складним. У місцях безпосереднього контакту твердих поверхонь перенесення тепла здійснюється через теплопровідність, а через зазори, заповнені рідиною чи газом, відбувається ще й через конвекцію та випромінення.

У відомих розробках теплофізичних приладів недостатньо уваги приділяють питанням впливу КТО на результат вимірювання, внаслідок чого прилади не забезпечують високої точності вимірювання (Pribory dlia teplofizicheskikh izmerenii, 1991; Platunov, et al., 1986). 3 огляду на це виникло багато задач: визначення КТО, дослідження їх впливу на точність вимірювання теплопро- відності, а також побудова приладів для вимірювання теплопровідності 3 урахуванням проведених досліджень для компенсації цього впливу.

Відомо, що передача тепла через зону контакту за рахунок теплопровідності відбувається двояко: через місця безпосереднього (фактичного) контакту тіл і через середовище, що заповнює простір між контактуючими поверхнями. Питома теплова провідність середовища $\alpha_{c}$ і фактичного контакту $\alpha_{m}$ увімкнені паралельно, тому питома провідність контакту $\alpha_{k}$ визначається їх сумою.

У літературних джерелах наводять емпіричну формулу для наближеного визначення питомої провідності контакту (Shlykov, et al., 1977)

$$
\alpha_{k}=\alpha_{c}+\alpha_{m}=\frac{\lambda_{c} \cdot Y}{2\left(h_{1}+h_{2}\right)}+8 \cdot 10^{3} \cdot \bar{\lambda}_{m} \cdot\left(\frac{p \cdot k}{3 \cdot \sigma_{B}}\right)^{0,86},
$$

де: $\bar{\lambda}_{m}=2 \cdot \lambda_{1} \cdot \lambda_{2} /\left(\lambda_{1}+\lambda_{2}\right) ; \lambda_{1}, \lambda_{2}-$ коефіцієнти теплопровідності для кожного матеріалу контактуючої пари, відповідно; $h_{1}, h_{2}-$ середні висоти мікронерівностей контактуючих поверхонь, що відповідають класу чистоти оброблення; $\lambda_{c}$ - теплопровідність середовища, що за-

\section{Інформація про авторів:}

Васильківський Ігор Степанович, канд. техн. наук, доцент, кафедра автоматизації та комп'ютерно-інтегрованих технологій. Email: vis@ukr.net; https://orcid.org/0000-0001-9172-4765

Фединець Василь Олексійович, д-р техн. наук, доцент, професор, кафедра автоматизації та комп'ютерно-інтегрованих технологій. Email: v.fedynets@ukr.net; https://orcid.org/0000-0002-9392-7491

Юсик Ярослав Петрович, канд. техн. наук, доцент, кафедра автоматизації та комп'ютерно-інтегрованих технологій. Email: yusik@ukr.net; https://orcid.org/0000-0001-5495-5206

Цитування за ДСтУ: Васильківський І. С., Фединець В. О., Юсик Я. П. Вимірювання теплопровідності листових матеріалів 3 урахуванням контактних теплових опорів. Науковий вісник НлтУ України. 2018, т. 28, № 5. С. 106-110.

Citation APA: Vasylkivskyi, I. S., Fedynets, V. O., \& Yusyk, Ya. P. (2018). Measurement of thermal conductivity of sheet materials concerning thermal contact resistance. Scientific Bulletin of UNFU, 28(5), 106-110. https://doi.org/10.15421/40280523 
повнює контактну зону; $p$ - контактний тиск; $\sigma_{B}-$ границя міцності для більш еластичного матеріалу; $Y$ відносна величина зазору, яку приймають для шліфованих поверхонь за нормальних умов, що дорівнює 3,33 ; $k=\left(15 \cdot 10^{6}\right) /\left(h_{1}+h_{2}\right)$ для $h_{1}+h_{2} \leq 10$ мкм; $\alpha_{m}-$ теплова провідність фактичного контакту.

3 формули (1) видно, що перший складник провідності визначається тільки властивостями середовища, що заповнює контакт, і чистотою оброблення контактуючих поверхонь, а другий - від теплопровідностей контактуючих матеріалів.

Для визначення КТО використано таку формулу:

$$
R_{k}=\frac{1}{\alpha_{k} \cdot S},
$$

де $S$ - площа контакту досліджуваної пари.

Розрахунок КТО за формулами (1) та (2) може призвести до значних похибок вимірювань, оскільки залежність КТО від масштабного та температурного факторів не досліджена. Окрім цього, не досліджена така залежність за грубого оброблення контактуючих поверхонь.

Як видно з наведеного вище, процес контактної провідності відрізняється великою складністю, оскільки залежить від низки різних за своїм характером чинників. Значна частина відомих дотепер робіт щодо контактного теплообміну має експериментальний характер. Розрахункові співвідношення, які трапляються в деяких дослідженнях, часто суперечливі і недостатньо теоретично обгрунтовані, тому розрахунок теплового опору контакту має певні труднощі. Отже, на сьогодні вивчення КТО за різних параметрів контактуючих поверхонь та навколишнього середовища в задачах вимірювання теплопровідності є одним з актуальних завдань сучасної теплофізики (Mishchenko, et al., 1999).

Мета роботи - експериментальне визначення значень КТО між зразками різних твердих матеріалів розробленим авторами пристроєм для вимірювання КТО, аналіз їх впливу на результат вимірювання теплопровідності різних матеріалів, створення на базі розроблених методологічних підходів методу вимірювання теплопровідності матеріалів та реалізація на його основі вимірювального перетворювача теплопровідності матеріалів, що дасть змогу усунути вплив КТО на результат вимірювання.

Виклад основного матеріалу. Для дослідження КТО автори дослідження розробили пристрої для вимірювання КТО з високою точністю. Принципову схему одного із таких пристроїв (Vasilkivskii, et al., 1988) наведено на рис. 1.

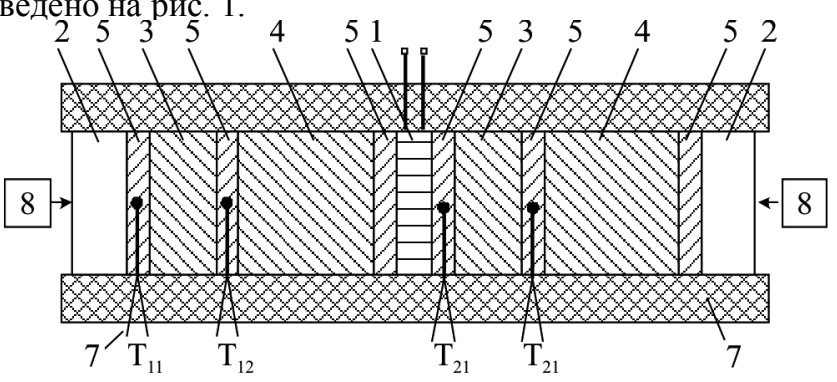

Рис. 1. Принципова схема пристрою для визначення КТО (взаємне розміщення досліджуваних пар зразків, джерела та приймачів тепла)

Пристрій складається із джерела тепла (електронагрівача) 1 , приймачів тепла 2 , між якими розміщені два пакети зразків 3 однаковими сумарними тепловими опорами. У кожному пакеті розміщені два типи контактуючих зразків з різних матеріалів - зразок першого типу і зразок другого типу (контактний опір між ними підлягає визначенню). Зразки другого типу в кожному пакеті розрізняються вдвічі за товщиною, а саме - зразок 3 вдвічі тонший, ніж зразок 4. Зразки 3 і 4 розташовуються в пакетах у різній послідовності відносно джерела тепла. Зразки 5 першого типу виконані однакової товщини і розташовані в кожній парі зразків ближче до джерела тепла. Два зразки 5 розташовані також між стоками тепла і пакетами зразків. Зразки 5 забезпечені вимірювачами 6 їх температури. Конструктивно вся збірка утримується в теплоізоляційному корпусі 7 . Осьове стискання збірки здійснюється механізмами 8 дозованого навантаження.

Визначення контактного теплового опору здійснюють у такій послідовності.

На джерело тепла 1 подають постійну теплову потужність, а приймачі тепла 2 підтримують за постійних температур, однакових між собою. Після встановлення стаціонарного режиму теплопередачі реєструють потужність джерела тепла 1, різницю температур, що встановилися між зразками 3 i 4, розташованими в різних пакетах відносно джерела тепла, і перепад температур на зразках 3 (як середнє арифметичне від суми двох виміряних значень на кожному зразку з метою зменшення похибки вимірювання).

Розглянемо пакет зразків зліва від джерела тепла (з урахуванням того, що зразок 3 вдвічі тонший, ніж зразок 4).

Значення температури $T_{12}$ на сторчаку зразка 4 таке:

$$
T_{12}=T_{H}-F_{1} \cdot\left(R_{5}+R_{k}+2 \cdot R+R_{k}\right),
$$

де: $T_{12}$ - вимірювана температура; $T_{H}$ - температура джерела тепла; $F_{1}$ - тепловий потік, що проходить через даний пакет зразків; $R_{5}-$ тепловий опір зразка 5; $R_{k}-$ КТО між зразками різних матеріалів; $2 \cdot R-$ тепловий опір зразка 4.

Значення температури $T_{22}$ на сторчаку зразка 3 таке:

$$
T_{22}=T_{H}-F_{2} \cdot\left(R_{5}+R_{k}+R+R_{k}\right),
$$

де, окрім відомих, $T_{22}$ - вимірювана температура; $F_{2}-$ тепловий потік, що проходить через даний пакет зразків; $R$ - тепловий опір зразка 4.

Оскільки теплові опори обох пакетів зразків однакові і температури приймачів тепла однакові, то

$$
F_{1}=F_{2}=F=W / 2,
$$

де $W$ - теплова потужність, що виділяється на джерелі тепла.

Різницю температур, що встановилася між зразками 3 i 4, розташованими в різних пакетах відносно джерела тепла, розраховують так:

$$
\Delta T_{1}=T_{12}-T_{22}=F \cdot R \text {. }
$$

Перепад температур $\Delta T_{2 л}$ на зразку 3 зліва від джерела тепла:

$$
\Delta T_{2 л}=F_{1} \cdot\left(R_{k}+R+R_{k}\right) .
$$

Аналогічно, перепад температур $\Delta T_{2 n}$ на зразку 3 справа від джерела тепла:

$$
\Delta T_{2 n}=F_{2} \cdot\left(R_{k}+R+R_{k}\right) .
$$

Перепад температур $\Delta T_{2}$ на зразках 3 визначаємо як середне арифметичне від суми двох виміряних значень на кожному зразку для зменшення похибки вимірювання, тоді отримаємо: 


$$
\Delta T_{2}=F \cdot\left(2 \cdot R_{k}+R\right) .
$$

Розв'язуючи систему рівнянь (6) i (9) за виміряними значеннями $\Delta T_{1}, \Delta T_{2}$ та $W$ визначають значення КТО за формулою

$$
R_{k}=\frac{\Delta T_{2}-\Delta T_{1}}{2 F}=\frac{\Delta T_{2}-\Delta T_{1}}{W} .
$$

Проводили дослідження КТО між різними твердими матеріалами як без використання змащування, так і 3 використанням змащування контактуючих поверхонь із застосуванням пристрою для вимірювання КТО. Результати експериментального визначення КТО наведено в таблиці. Вони показують, що їх значення змінюються в межах від 1,1 до 0,72 К/Вт - за відсутності змащування на контактуючих поверхнях, і від 0,31 до $0,18 \mathrm{~K} / \mathrm{BT}$ - за змащування контактуючих поверхонь змазкою ПФМС-4, тобто заповнення міжконтактного простору зменшує КТО приблизно в 3-3,5 рази.

Таблиця. Результати експериментального визначення

\begin{tabular}{|c|c|c|c|c|c|c|c|}
\hline \multirow{4}{*}{$\begin{array}{c}\text { Матеріал, } \\
\text { що контак- } \\
\text { тує } 3 \text { мідною } \\
\text { пластиною }\end{array}$} & \multirow{4}{*}{$\begin{array}{c}\text { Чистота } \\
\text { оброблен- } \\
\text { ня, } R_{z}, \\
\text { мкм }\end{array}$} & \multicolumn{6}{|c|}{ Тиск, МПа } \\
\hline & & 0,5 & 1,0 & 2,0 & 0,5 & 1,0 & 2,0 \\
\hline & & \multicolumn{6}{|c|}{ Значення КТО } \\
\hline & & \multicolumn{3}{|c|}{ товнення } & \multicolumn{3}{|c|}{$\begin{array}{c}\text { із заповненням } \\
\text { ПФМС-4 }\end{array}$} \\
\hline \multirow{2}{*}{$\begin{array}{l}\text { Органічне } \\
\text { скло }\end{array}$} & & $\overline{10}$ & 1,02 & 0,98 & 0,31 & 0,29 & 0,28 \\
\hline & & 85 & 0,83 & \begin{tabular}{|l|}
0,83 \\
\end{tabular} & 0,24 &, 23 & 0,23 \\
\hline \multirow{2}{*}{ Сплав ВТ-6 } & & 6 & 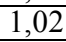 & 1 & 0,29 & 0,28 & 0,2 \\
\hline & & & 0 & & 2 & 0,22 & 0,22 \\
\hline & & & 1,04 & 0 & 0,28 & 0,26 & 0,27 \\
\hline & & & 0, & & 0,2 & 0,20 & 0,20 \\
\hline \multirow{2}{*}{$\begin{array}{l}\text { Низьковуг- } \\
\text { лецева сталь }\end{array}$} & & & 0,93 & 0,9 & 0,27 & 0,27 & 0,26 \\
\hline & 1,0 & $\overline{0,78}$ & 0,76 & $\overline{0,72}$ & 0,19 & 0,18 & 0,1 \\
\hline
\end{tabular}
KTO

Для поліпшення контактування двох поверхонь i зниження КТО може бути використано заповнення контактної зони середовищем, що має теплопровідність, близьку до теплопровідності металів. Поширеним методом зменшення КТО є введення в зону контакту порошкоподібних і в'язких речовин з доброю теплопровідністю: паст, мастил, рідин.

Отже, проведені дослідження дають підстави зробити висновок, що КТО залежить переважно від якості оброблення контактуючих поверхонь, використання змащування і дуже мало залежить від теплопровідності, механічних властивостей контактуючих матеріалів та контактного тиску.

Знехтувати впливом КТО на результат вимірювання у визначенні коефіцієнта теплопровідності різних матеріалів (особливо високотеплопровідних) не можна, оскільки КТО співрозмірні з тепловими опорами досліджуваних зразків. Так, наприклад, проведення досліджень без врахування впливу КТО матеріалів 3 коефіцієнтом теплопровідності $\lambda>10 \mathrm{BT} /(\mathrm{м} \cdot \mathrm{K})$ призведе до похибки вимірювань 15 \% та більше (Kurepin, 1982).

Для виключення впливу КТО на результат вимірювання теплопровідності ми розробили вимірювальний перетворювач теплопровідності листових матеріалів у діапазоні від 40 до $400 \mathrm{BT} /($ м.К) на основі зрівноваженої мостової TBC, принципову схему якого наведено на рис. 2.

Джерело тепла 1 формує вузькоспрямований потік випромінювання в інфрачервоній області спектра на поверхню досліджуваної пластини 3 , яка знаходиться в контакті з поверхнями двох пакетів зразків. Пакети зразків зафіксовані на поверхні стоку тепла 2. Вони складаються 3 тепломірних елементів 4, температуровирівню- вальних пластин 5, опорних зразків 6 і 7 з різними тепловими опорами та контактних елементів 8, виготовлених з високотеплопровідної гуми. Досліджувана пластина 3 притискається до пакетів підпружиненими фіксаторами 9, закріпленими на корпусі 10, шляхом переміщення стоку тепла 2 вздовж направляючих 113 допомогою гайки 12 і гвинта 13, який обертається ручкою 14.

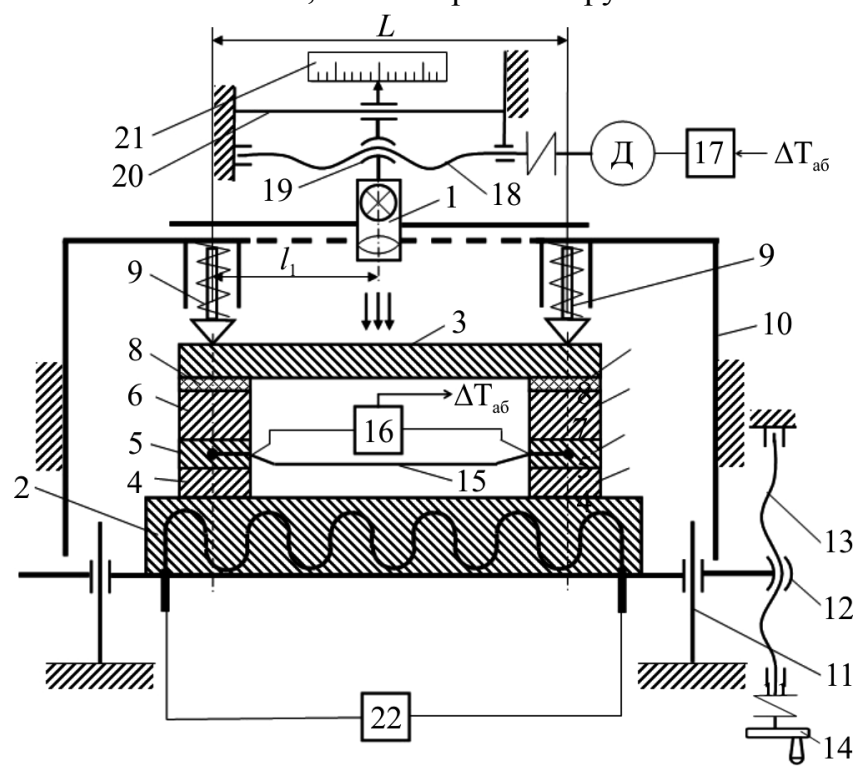

Рис. 2. Принципова схема вимірювального перетворювача теплопровідності листових матеріалів

У температуровирівнювальних пластинах 5 розміщені злюти диференційної термопари 15 , яка підключена до підсилювача 16 і сигнал $\Delta T_{a \sigma} 3$ якого поступає на регулюючий блок 17, що керує роботою двигуна Д. Двигун приводить в рух гвинт 18, що змінює положення гайки 19 вздовж направляючої 20 і, цим самим положення джерела тепла $1 l_{1}$ доти, поки сигнал диференційної термопари $\Delta T_{a б}$ не буде дорівнювати нулю. Тоді результат вимірювання зчитується зі шкали 21. Температура стоку тепла 2 задається 3 допомогою термостату 22.

Розглянемо мостову зрівноважену ТВС зі зрівноваженням теплових потоків, що проходять через опорні зразки, яка лежить в основі цього перетворювача теплопровідності. Схему з'єднання теплових опорів і КТО в ній наведено на рис. 3 .

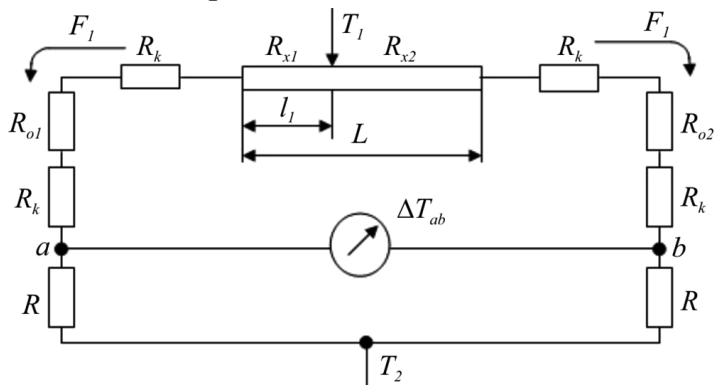

Рис. 3. Схема з'єднання теплових опорів і КТО, розподілу теплових потоків та температур у зрівноваженій мостовій ТВС зі зрівноваженням теплових потоків, що проходять через опорні зразки

Для цієї ТВС можна записати таку систему рівнянь:

$$
\left\{\begin{array}{l}
F_{1}=\frac{T_{1}-T_{a}}{R_{x 1}+R_{k}+R_{o 1}+R_{k}}=\frac{T_{a}-T_{2}}{R} \\
F_{2}=\frac{T_{1}-T_{b}}{R_{x 2}+R_{k}+R_{o 2}+R_{k}}=\frac{T_{b}-T_{2}}{R}
\end{array} .\right.
$$


Умови рівності теплових потоків, що проходять через еталонні зразки, досягають шляхом дії теплового потоку на обмежену зону досліджуваного зразка і переміщенням місця дії теплового потоку (джерела тепла). Очевидно, що за виконання умов рівності теплових потоків, які проходять по різних теплопровідних колах $\left(F_{1}=F_{2}\right)$, маємо $\Delta T_{a b}=0$.

Розв'язуючи систему рівнянь, можна записати таке рівняння рівноваги:

$$
R_{x 1}+R_{k}+R_{o 1}+R_{k}=R_{x 2}+R_{k}+R_{o 2}+R_{k},
$$

або після нескладних перетворень отримуємо

$$
R_{x 1}-R_{x 2}=R_{o 2}-R_{o 1}
$$

Звідси, подавши значення теплових опорів елементів ТВС через їх геометричні розміри та коефіцієнт теплопровідності, отримуємо формулу для визначення коефіцієнта теплопровідності досліджуваного зразка

$$
\lambda_{x}=\frac{L-2 l_{1}}{S_{x}\left(\frac{l_{01}}{\lambda_{01} \cdot S_{01}}-\frac{l_{02}}{\lambda_{02} \cdot S_{02}}\right)},
$$

де: $\lambda_{x}, \lambda_{o 1}, \lambda_{o 2}-$ коефіцієнти теплопровідності досліджуваного, першого та другого опорних зразків, відповідно; $L$ - відстань між опорними зразками; $l_{1}-$ відстань від середини місця дії теплового потоку до одного із опорних зразків; $l_{o 1}, l_{o 2}-$ товщина першого та другого опорних зразків, відповідно; $S_{x}, S_{o 1}, S_{o 2}$ - площа поперечного перерізу досліджуваного, першого та другого опорних зразків, відповідно.

Після нескладних перетворень отримуємо

$$
\lambda_{x}=A-B \cdot l_{1},
$$

де $A$ і $B$ - константи приладу, які знаходяться при градуюванні, причому

$$
A=\frac{L_{1}}{S_{x}\left(\frac{l_{61}}{\lambda_{61} \cdot S_{61}}-\frac{l_{62}}{\lambda_{62} \cdot S_{62}}\right)}, B=\frac{2}{S_{x}\left(\frac{l_{61}}{\lambda_{61} \cdot S_{61}}-\frac{l_{62}}{\lambda_{62} \cdot S_{62}}\right)} .
$$

Для градуювання перетворювача використовували стандартні зразки з міді, низьковуглецевої і нержавіючої сталей та сплаву ВТ-6.

Проведені дослідження теплопровідності пластин, виготовлених 3 алюмінію, алюмінієвих сплавів, різних марок латуні, бронзи, сталі. Гранична допустима похибка вимірювання у всьому діапазоні не перевищує 8 \%, що вдалось досягнути за рахунок виключення по- хибок від впливу контактних теплових опорів та інших неінформативних впливів на результат вимірювання.

Висновки. Розглянуто питання впливу КТО на точність вимірювання теплопровідності матеріалів та наведено конструкцію пристрою для визначення значень КТО між різними матеріалами. За результатами виконаних експериментальних досліджень встановлено, що знехтувати впливом КТО на результат вимірювання у визначенні коефіцієнта теплопровідності різних матеріалів (особливо високотеплопровідних) не можна, оскільки він співмірний з тепловими опорами досліджуваних зразків. Для виключення впливу КТО на результат вимірювання теплопровідності розроблено вимірювальний перетворювач теплопровідності листових матеріалів. Висока точність вимірювання, стабільність показів i простота конструкції розробленого вимірювального перетворювача теплопровідності для досліджуваних зразків листової форми роблять його перспективним у плані серійного випуску, як робочого засобу вимірювання теплопровідності. Перетворювач дасть змогу значно підвищити надійність і зменшити собівартість теплофізичних вимірювань, розв'язати ряд актуальних задач, не вирішених досі в галузі теплофізичного приладобудування.

\section{Перелік використаних джерел}

A. S. № 1413499 SSSR, MKI G 01 N 25/18. Sposob opredeleniia kontaktnogo termicheskogo soprotivleniia. I. S. Vasilkivskii., E. P. Pistun., Ia. T. Rogotckii; opubl. 30.07.88, Biul. №28. 2 p. [In Russian].

Kurepin, V. V. (1982). Kontaktnye termicheskie soprotivleniia pri teplofizicheskikh izmereniiakh. Inzhenerno-fizicheskii zhurnal, 42(4), 615-622. [In Russian].

Mishhenko, S. V., Churikov, A. A., \& Shishkina G. V. (1999). Kontaktnye termicheskie soprotivleniia pri opredelenii teplofizicheskikh svoistv razlichnykh materialov. Tambov: TGTU. 26 p. Dep. v VINITI, g. Moskva, № 3891 - V 99 ot 29.12.99. [In Russian].

Platunov, E. S., Buravoi, S. E., Kurepin, V. V., \& Petrov, G. S. (1986). Teplofizicheskie izmereniia i pribory. Leningrad: Mashinostroenie, Leningr. otd-nie, 256 p. [In Russian].

Pribory dlia teplofizicheskikh izmerenii. (1991). Katalog It-ta problem energosberezheniia NAN Ukrainy. Kyiv, 57 p. [In Russian].

Shlykov, Iu. P., Ganin, E. A., \& Tcarevskii, S. N. (1977). Kontaktnoe termicheskoe soprotivlenie. Moscow: Energiia, 328 p. [In Russian].

И. С. Васильковский, В. А. Фединец, Я. П. Юсык

Национальный университет "Львовская политехника", г. Львов, Украина

\section{ИЗМЕРЕНИЕ ТЕПЛОПРОВОДНОСТИ ЛИСТОВЫХ МАТЕРИАЛОВ С УЧЕТОМ КОНТАКТНЫХ ТЕПЛОВЫХ СОПРОТИВЛЕНИЙ}

Рассмотрены вопросы влияния контактных тепловых сопротивлений (КТС) на точность измерения теплопроводности материалов. Приведена конструкция устройства для определения значений КТС. В основе устройства является пакет из двух пар плоских образцов, размещенных в разной последовательности между источником тепла и приемниками тепла равной температуры. Один из образцов во всех парах имеет одну и ту же толщину, второй образец в двух парах пакета отличается по толщине вдвое. Регистрируют тепловой поток через пакеты, разницу температур между серединными образцами пакетов и перепад температур на тонком образце и по полученным данным рассчитывают искомую величину. Представлены результаты экспериментального определения КТС между различными материалами. Показано, что пренебречь влиянием КТС на результат измерения при определении коэффициента теплопроводности различных материалов (особенно высокотеплопроводных) нельзя, поскольку он соизмерим с тепловыми сопротивлениями исследуемых образцов. С целью исключения этого влияния на результат измерения теплопроводности разработан измерительный преобразователь для измерения теплопроводности материалов на основе мостовой тепловой измерительной схемы. Приведены схема соединения тепловых сопротивлений и КТС, распределения тепловых потоков и температур в уравновешенной мостовой тепловой измерительной схеме и принципиальная схема измерительного преобразователя теплопроводности листовых материалов.

Ключевые слова: коэффициент теплопроводности; мостовая тепловая измерительная схема; исследуемый образец; эталонный образец; тепловое сопротивление контакта; площадь контакта. 
I. S. Vasylkivskyi, V. O. Fedynets, Ya. P. Yusyk

\section{MEASUREMENT OF THERMAL CONDUCTIVITY OF SHEET MATERIALS} CONCERNING THERMAL CONTACT RESISTANCE

Measurement of thermal conductivity of materials without taking into account the influence of thermal contact resistance leads to significant measurement errors. As a result, a number of problems related to the determination of thermal contact resistance, the study of their influence on the accuracy of the measurement of heat conductivity, as well as the construction of devices for measuring the thermal conductivity, taking into account the research carried out in order to compensate for the influence of contact thermal resistance. The design of the device developed by the authors for determining the values of thermal contact resistance between different materials is given. Between the heat source and the heat receivers, two packages of two pairs of flat samples are arranged in different sequences. One of the samples in two pairs package varies in thickness by half, the second sample has the same thickness and mounted sensor temperature. After installing the stationary thermal regime, the values of the heat flow through the packages, the temperature difference between the middle samples of the packages and the temperature difference on the finer sample are measured. On the basis of the received data, the desired value is calculated. Measurements of thermal contact resistance between different materials and experimental results are presented. It is shown that the values of the thermal resistance of the contacts are proportional to the thermal supports of the investigated samples; therefore it is impossible to ignore their influence on the result of measurement in determining the coefficient of thermal conductivity of different materials. In order to increase the accuracy of measuring the thermal conductivity due to the elimination of the influence of contact thermal impedance on the measurement result, a measuring transducer for measuring the thermal conductivity of sheet materials on the basis of a balanced bridge thermal measuring circuit is developed. The principal scheme of the measuring transducer of heat conductivity of sheet materials and the scheme of connection of thermal resistances and thermal contact resistance, distribution of heat fluxes and temperatures in the balanced bridge thermal measuring scheme underlying this transducer are given. High accuracy of measurement, stability of displays and simplicity of design of the developed measuring transducer of thermal conductivity for the investigated samples of sheet form make it perspective in terms of serial release, as a working means of measuring the thermal conductivity.

Keywords: thermal conductivity coefficient; bridge thermal measuring circuit; investigated sample; reference sample; thermal resistance of the contact; contact area. 